\title{
Introduction: Drinking, Driving, and Health Promotion
}

\author{
David A. Sleet, PhD \\ Alexander C. Wagenaar, PhD \\ Patricia F. Waller, PhD
}

Alcohol-impaired driving* continues to be one of the nation's most serious public health problems. There is now little question that consumption of alcoholic beverages, even in amounts much lower than the legal limit, is a major contributor to motor vehicle crashes and the casualties and injuries that result. ${ }^{1,2}$ One study estimates that eliminating alcohol would reduce traffic fatalities by 47 percent $( \pm 4 \%$ ), equivalent to a reduction of between 20,000 and 24,000 fatalities annually. ${ }^{3}$ There is no doubt that a reduction in alcohol-impaired driving would result in a substantial savings of human lives and resources, worldwide. ${ }^{4}$

\section{THE RISK OF ALCOHOL-IMPAIRED DRIVING}

The risk of involvement in a car crash increases rapidly as the concentration of alcohol in the blood increases. A driver with a blood alcohol concentration of .05 $\mathrm{g} / \mathrm{dL}$ is about twice as likely to be involved in a fatal traffic crash than a driver who has not consumed any alcoholic beverages. The risk is about seven times greater for a driver with a $.10 \mathrm{~g} / \mathrm{dL}$ blood alcohol concentration, and 25 times greater at .15 $\mathrm{g} / \mathrm{dL}^{5}$ Consumption of three drinks in an hour will put the typical male over the .05

* Different terms are used in the literature to describe driving after excessive drinking, such as driving while intoxicated, driving under the influence of alcohol, driving while impaired, etc. For convenience, the term "driving while intexicated" (DWI) is used throughout this theme issue to indicate a legal level of blood alcohol concentration, usually at or above .10 grams of alcohol per deciliter of blood $(0.10 \mathrm{~g} / \mathrm{dL}$ : commonly referred to as $.10 \%$ blood alcohol concentration $)$ in which the driver is considered legally impaired.

David Sleet is Professor, Department of Health Science and Adjunct Professor, Division of Health Promotion, Graduate School of Public Health, San Diego State University, California.

Alexander Wagenaar is Head of the Injury Analysis and Prevention group at the Transportation Research Institute and Associate Research Scientist in the School of Public Health, University of Michigan, Ann Arbor.

Patricia Waller, former Director of the Injury Prevention Research Center, University of North Carolina, Chapel Hill, is currently Director, University of Michigan Transportation Research Institute, Ann Arbor.

Address reprint requests to David Sleet, Department of Health Science, San Diego State University, San Diego, CA 92182. 
$\mathrm{g} / \mathrm{dL}$ level. For a 110 pound woman, one and a half drinks in an hour will typically produce a $.05 \mathrm{~g} / \mathrm{dL}$ level, and three drinks will produce the $.10 \mathrm{~g} / \mathrm{dL}$ level. ${ }^{6}$

\section{DIFFERENCES IN RISK}

The relationships among the amount of alcohol consumed, blood alcohol concentration, performance decrement, and risk of crash involvement are complex. Blood alcohol concentration (BAC) obtained by a given dose of alcohol is a function of one's weight, proportion of adipose or fat tissue, digestive track metabolism, presence of food in the stomach, and other factors. For example, because alcohol is water soluble and not fat soluble, and women typically have a higher proportion of total weight that is adipose tissue, women typically will obtain a higher blood alcohol concentration from a given dose of alcohol than men, even if they are of the same weight. ${ }^{7}$

The degree of increased crash risk at a given blood alcohol concentration varies by demographic and behavioral characteristics of individuals. Youth are more impaired at a given blood alcohol concentration than older drivers, and their risk of involvement in crashes increases more rapidly at higher alcohol concentrations than older drivers.

Evidence from the FARS (Fatal Accident Reporting System) files indicates that only $10 \%$ of very young drivers (under 16) fatally injured in crashes have BACs of 0.10 $\mathrm{g} / \mathrm{dL}$ or higher, yet $29 \%$ of $16-19$-year olds and $37 \%$ of drivers age $20-24$ have BACs of $.10 \mathrm{~g} / \mathrm{dL}$ or above. Thereafter, it gradually declines with only $7 \%$ of drivers age 70 and older showing such high alcohol levels. ${ }^{8}$ There is also evidence that alcohol differentially affects the performance of older people. Parker and Noble ${ }^{9}$ concluded that, in older people when other relevant factors are controlled "... with increasing age, conceptual processes become increasingly vulnerable to the effects of alcohol." Finally, an older person of a given weight is likely to reach a higher BAC from a specified quantity of alcohol than a younger person of the same weight. ${ }^{10}$

There are also genetic differences among populations and individuals that predispose them to greater or lesser vulnerability to developing problems with alcohol. ${ }^{11}$ The person who can "hold his liquor" (consume large quantities of alcohol with no apparent discomfort or effect), for example, is probably at increased risk of addiction to alcohol.

Finally, there is research documenting the potentiating effects of alcohol on injury once a crash occurs. For a given impact, an organism with alcohol will sustain greater injury than one without alcohol. ${ }^{12,13}$ Thus alcohol is associated with injury in two major ways. First, alcohol impairs performance so that a driver is more likely to crash. Second, in a crash of given severity, vehicle occupants who have been drinking are likely to sustain greater injury than those who have not been drinking. The overall difference in probability of serious injury or death from a crash is roughly twofold with alcohol present, but in certain types of crashes, the differences between those with and without alcohol are greater than fourfold.

Many factors influence the exact effects of alcohol consumption in any given case, ${ }^{14,15}$ but there is little question that risk to the public's health increases significantly when people drive after having more than two drinks in an hour, regardless of age, sex, or other relevant variables. 


\section{ALCOHOL-IMPAIRED DRIVING AND HEALTH PROMOTION}

Public health has been a latecomer to efforts to reduce alcohol-impaired driving. In most instances, the traffic safety and criminal justice communities have taken the lead, using deterrent strategies such as increasing traffic surveillance and enforcement, and stiffening prosecution, adjudication, and sanctioning for DWI offenses. Alcoholimpaired driving has traditionally been considered a major highway safety problem. Only recently has it been accepted as a public health problem ${ }^{16,17}$ amenable to health promotion approaches. ${ }^{18,19}$

The behavior of driving while intoxicated, or driving after drinking, is not only shaped by individual choice and motivation, but also strongly associated with organizational, economic, environmental, and social factors. Therefore, approaches that use education alone to bring about change in DWI behavior are likely to have limited or no success. The reader is reminded, however, that each preventive intervention builds on the strength of every other. The health promotion approach recognizes the importance of using a multidisciplinary approach in DWI prevention efforts. The long-term view of change favors the culmulative effects of interventions over time.

Health promotion is defined by Green" as "any combination of educational, organizational, and policy supports for behavior and conditions of living conducive to health ...". The conditions of living that health promotion seeks to change are those social and environmental factors that may influence behavior or health itself. Changing behavior and societal practices with regard to DWI will require actions by legislators, employers, citizen groups, schools, taverns, and others. Individual and community actions, fostered by education, stimulated by changing social norms, and encouraged through public policy, are the immediate objects of health promotion.

The articles assembled for this theme issue of Health Education Quarterly embody a broad array of health promotion approaches to impaired driving. The epidemiology of the problem of alcohol-impaired driving is discussed using fatal crash data of the National Highway Traffic Safety Administration, (Fell and Nash) and self-report/ behavioral risk factor data of the Centers for Disease Control (Smith, et al.). Psychological theory of attribution of responsibility for alcohol-related motor vehicle crashes is explored in an article by DeJoy. Situational factors increasing risk for DWI among youth are discussed by Vegega and Klitzner, reporting on research conducted within the transportation sector.

Bach, DeCicco and Malfetti summarize findings from focus group interviews among young drivers to better understand how youth make decisions on whether and when to drink and drive. A theoretical model useful in planning interventions to prevent DWI is presented in a paper by Simons-Morton and his colleagues. Public policy alternatives are outlined by Farrell. A summary of what is known about the effects of server intervention programs and ideas for future research is presented by Saltz. Finally, we have included an annotated resource guide to DWI programs and materials for those who want further information, or wish to coordinate their efforts with existing networks.

No attempt was made here to address the significance of DWI treatment and rehabilitation programs to the overall effort to control drinking and driving. These topics have been covered elsewhere. ${ }^{21,22}$ Other topics which are not fully covered in this issue, but which may be of vital interest to those in traffic safety and health promotion, include the role of the mass media in encouraging alcohol use, citizen advocacy for effecting change, engineering modifications to reduce crashes and resulting 
injury, enforcement and judiciary processes, and the contribution of emergency medical services to injury control. Background articles on these topics have been recently published. ${ }^{23-25}$

The convergance of traffic safety and public health interests in preventing DWI, uniquely represented in this issue of the Quarterly, will stimulate new research and programs leading to more effective control of alcohol-impaired driving. ${ }^{26}$ Health promotion plays a key role in this process as the authors of these reports have aptly demonstrated.

Support for this theme issue was provided, in part, by Contract No. DTNH22-87C-05183 from the Office of Alcohol Programs, National Highway Traffic Safety Administration (U.S. Department of Transportation). Ms. Joan White Quinlan of the National Highway Traffic Safety Administration (NHTSA) was especially instrumental in bringing this theme issue to fruition. Her insights in to both traffic safety and public health have resulted in major advances in the public health response to alcohol-impaired driving. Others involved in assisting the project were Bob Vollinger, Tracy Tripp, and Andrea Wylan. Special thanks go to Larry Green for our lively discussions on an early draft of the Introduction, Lloyd Kolbe for his encouragement in pursuing this topic, and to the board of guest reviewers for their diligent work reviewing the manuscripts.

\section{References}

1. Committee on Benefits and Costs of Alternative Federal Blood Alcohol Concentration Standards for Commercial Vehicle Operators. Zero Alcohol and Other Options. Washington, D.C., Transportation Research Board, National Research Council, 1987.

2. Donelson AC, Beirness DJ, Simpson HM: Beverage Alcohol Concentration and Traffic Safety. Ottawa, Ontario, Traffic Injury Research Foundation of Canada, 1988.

3. Evans L. The Fraction of Traffic Fatalities Attributable to Alcohol. General Motors Research Laboratories Report \#GMR-6636, Warren, MI, 1989.

4. Trinca CW, Johnston IR, Campbell BJ, Haight FA, Knight PR, Mackay GM, McLean AJ, Petrucelli E: Reducing Traffic Injury: A Global Challenge. Melbourne, Australia. Royal Australasian College of Surgeons, 1988.

5. National Highway Traffic Safety Administration: Alcohol and Highway Safety 1984: A review of the State of Knowledge. Washington, DC, U.S. Department of Transportation (report DOT-HS-806-569), 1985.

6. Fisher HR, Simpson RI, and Kapur BM: Calculation of blood alcohol concentration by sex, weight, number of drinks and time. Canadian Journal of Public Health, 78: 300-304, 1987.

7. Burns $\mathrm{M}$ and Moskowitz $\mathrm{H}$ : Methods for Estimating Expected Blood Alcohol Concentration. Los Angeles, CA, Southern California Research Institute (DOT HS 805 563), 1980.

8. Cerrelli EC: Alcohol in Fatal Accidents. National Estimates-U.S.A. Washington, DC: US Dept of Transportation, (DOT HS 806371 ), 1983.

9. Parker ES and Noble EP: Alcohol and the aging process in social drinkers. $J$ Stud Alc 41: 170-178, 1980.

10. Vestal RE, McGuire EA, Tobin JD, Andres R, Norris AH, and Mazey E: Aging and ethanol metabolism. Clin Pharmac Ther 21:343-354, 1977. 
11. Goodwin DW: Alcoholism and heredity: A review and hypothesis. Arch Gen Psych 36: 57-61, 1979.

12. Waller PF, Hansen AR, Stutts JC, Popkin CL: Alcohol: A potentiating factor in motor vehicle crash injury. in Alcohol, Accidents and Injuries, Society of Automotive Engineers, February 1986, pp 53-61.

13. Waller PF, Stewart JR, Hansen AR, Stutts JC, Popkin CL, Rodgman EA: The potentiating effects of alcohol on driver injury: Journal of the American Medical Association 256: 1462-1466, 1986.

14. Perrine MW, Waller JA. Harris LS: Alcohol and Highway Safety: Behavioral and Medical Aspects. Washington, DC. US Dept of Transportation. (DOT HS 800 599) 1971.

15. Wagenaar AC: Alcohol, Young Drivers and Traffic Accidents. Lexington, MA, Lexington Books, D.C. Heath and Co., 1983.

16. Dickman FB: Alcohol and highway safety in a public health perspective. Public Health Reports 103: 653-658, 1988.

17. Committee on Public Health, New York Academy of Medicine: Proceedings of symposium on motor vehicle injuries. Bulletin of the New York Academy of Medicine 64: 605-866, 1988.

18. Simpson HM: Community-based approaches to highway safety: Health promotion and drinking-driving. Drug and Alcohol Dependence 20: 27-37, 1987.

19. Geller ES, Elder JP, Hovell MF. Sleet DA: Behavioral Approaches to DrinkingDriving Interventions, in WB Ward and FM Lewis (eds.). Advances in Health Education and Promotion Vol III, Greenwich, Conn, JAI Press, Inc., (in press).

20. Green LW: Community Health. St. Louis. Times Mirror/Mosby, 6th Edition, (in press).

21. Foon AE: The effectiveness of drinking-driving treatment programs: A critical review. International Journal of the Addictions, 23: 151-174, 1988.

22. Valle SK: Drunk Driving in America: Strategies and Approaches to Treatment. New York: Haworth Press, 1986.

23. Graham JD (ed): Preventing Automobile Injury. Dover, MA. Auburn House, 1988.

24. U. S. Department of Health and Human Services, U.S. Public Health Service, Office of the Surgeon General: Proceedings of the Surgeon General's Workshop on Drunk Driving. Rockville, MD, USDHHS, 1989.

25. National Committee for Injury Prevention and Control (with Education Development Center Inc.): Injury Prevention: Meeting the Challenge. New York, Oxford University Press, 1989.

26. National Highway Traffic Safety Administration: Consensus Report on Impaired Driving. Washington. DC. US Dept of Transportation, (DOT HS 807 390), March 1989. 